Rhode Island College

Digital Commons @ RIC

Master's Theses, Dissertations, Graduate

Master's Theses, Dissertations, Graduate Research and Major Papers Overview

Research and Major Papers

$5-12-2020$

\title{
An Educational Module Related to Medical Marijuana for APRN
}

Lauren E. Slater

Follow this and additional works at: https://digitalcommons.ric.edu/etd

Part of the Nursing Commons

\section{Recommended Citation}

Slater, Lauren E., "An Educational Module Related to Medical Marijuana for APRN" (2020). Master's Theses, Dissertations, Graduate Research and Major Papers Overview. 368.

https://digitalcommons.ric.edu/etd/368

This Major Paper is brought to you for free and open access by the Master's Theses, Dissertations, Graduate Research and Major Papers at Digital Commons @ RIC. It has been accepted for inclusion in Master's Theses, Dissertations, Graduate Research and Major Papers Overview by an authorized administrator of Digital Commons @ RIC. For more information, please contact digitalcommons@ric.edu. 


\section{DEVELOPMENT OF AN EDUCATIONAL \\ MODULE RELATED TO MEDICAL MARIJUANA \\ FOR ADVANCED PRACTICE REGISTERED NURSE CURRICULUM}

by

Lauren E. Slater RN, BSN

A Major Paper Submitted in Partial Fulfillment

of the Requirements for the Degree of

Master of Science in Nursing

in

The School of Nursing

Rhode Island College

2020 


\begin{abstract}
As the prevalence of cannabis use increases, it is clear that advanced practice registered nurses (APRN) will be caring for patients who either use cannabis to treat a qualifying condition or use it recreationally. Current curriculum lacks cannabis-specific knowledge necessary for APRNs to provide safe and appropriate care to patients using cannabis. The purpose of this project was to evaluate the impact of a teaching module intended to provide essential knowledge and clinical implications of medical cannabis for the APRN student. An educational module was developed based on The National Council of State Boards of Nursing (NCSBN) National Nursing Guidelines for Medical Marijuana Education in APRN Nursing Programs. A pre- and post-video survey consisting of nine knowledge items and one additional perceived importance question was developed and the project was reviewed by the Rhode Island College IRB as a quality improvement project. Rhode Island College APRN students were asked to participate by completing the pre-video survey, watching the educational video, and completing the post-video survey. A total of 24 students completed the pre-video survey and 19 students completed the post-video survey. The mean knowledge scores prior to the educational video ranged from "very poor" to "undecided" and improved to "somewhat good" to "very good" following the video. All participants perceived the importance of integrating cannabis education into the APRN curriculum as "moderately" or "extremely" important on both pre- and post-video surveys. Nursing regulatory organizations, together with accredited academic institutions, must evaluate current gaps in curriculum and work towards integrating cannabis-specific content. APRN students must have essential knowledge and clinical implications of medical cannabis in order to provide safe and appropriate care to patients using cannabis.
\end{abstract}




\section{Table of Contents}

Background/Statement of the Problem .................................................................... 1

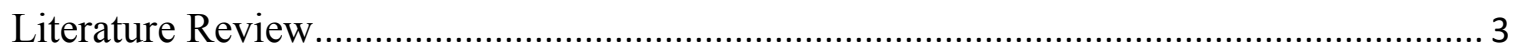

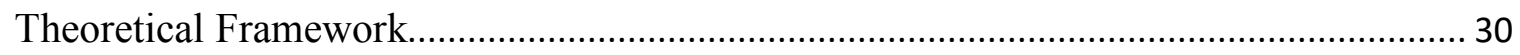

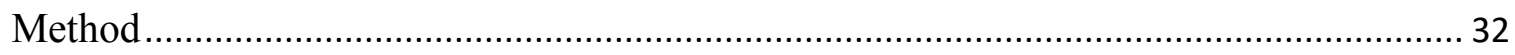

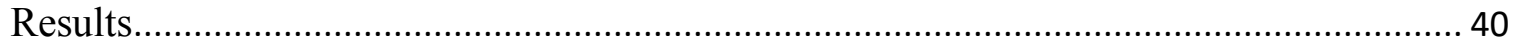

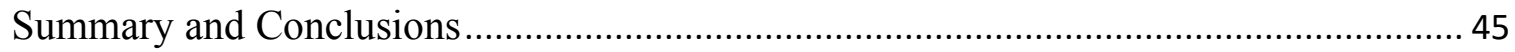

Recommendations and Implications for Advanced Nursing Practice ............................. 49

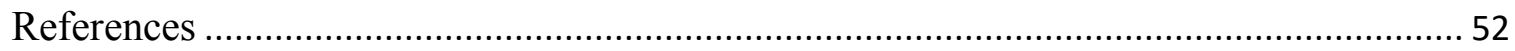

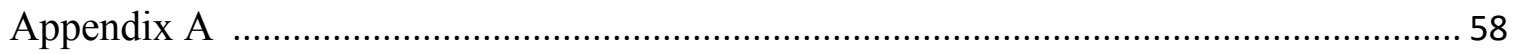


Development of an Educational Module related to Medical Marijuana for Advanced Practice Registered Nurse Curriculum

\section{Background/Statement of the Problem}

Marijuana, also known as cannabis, has been present in our society throughout history with varying levels of acceptance and legality (Bridgeman \& Abazia, 2017). Public support for cannabis use over the past 10 years or so has led to a significant increase in its use. As of March 2020, 33 states, District of Columbia, Guam, Puerto Rico, and the U.S. Virgin Islands have approved medical marijuana/cannabis programs for patients with certification of a qualifying condition, while 14 states and territories have approved marijuana for adult recreational use (National Conference of State Legislatures (NCSL), 2020).

Due to rapid change in societal attitudes towards cannabis and its increasing use, nurses and advanced practice registered nurses (APRNs) will undoubtedly be caring for patients who either use cannabis to treat a qualifying condition or use it recreationally. As cannabis has been classified as a Schedule I Controlled Substance following the Federal Comprehensive Drug Abuse Prevention and Control Act of 1970, research on efficacy, indications, and long-term effects has been limited and lacking. Pre-licensure and APRN curriculum have subsequently lacked instruction related to the pharmacology, physiologic effects, uses, neurological symptoms, drug-to-drug interactions, and adverse effects of cannabis.

In order to better ensure that APRNs provide safe and appropriate patient care, cannabis-specific curriculum content is necessary. Curriculum must not only provide knowledge related to the current state of legalization and research, but also the 
endocannabinoid system, pharmacology, and most importantly, safety considerations for the patient using cannabis. The purpose of this project is to evaluate the impact of a teaching module intended to provide essential knowledge and clinical implications of medical cannabis for the APRN student.

Next, the review of the literature will be presented. 


\section{Literature Review}

\section{The Cannabis Plant and Historical Use}

Cannabis is a generic term used to describe plants belonging to the genus Cannabis sativa, Cannabis indica, and Cannabis ruderalis. The 1961 United Nations Single Convention on Narcotic Drugs more specifically defined cannabis as "the flowering or fruiting tops of the cannabis plant from which resin has not been extracted" (Madras, 2015, p. 3). With origins dating back more than 5,000 years, cannabis had been widely used as a patent medication in the United States during the $19^{\text {th }}$ and early $20^{\text {th }}$ centuries. Cannabis was described in the $3^{\text {rd }}$ edition of the U.S. Pharmacopoeia (U.S.P.) for the first time in 1850 under the name of Extractum Cannabis or Extract of Hemp. More than 20 prescription medications containing cannabis were sold at U.S. pharmacies between 1850 and 1937 and U.S. medical practices used these medications to treat a wide range of ailments (Bridgeman \& Abazia, 2017).

Regulation of cannabis and increased restrictions began around 1906 after which prohibitions and state-by-state regulations eventually led to the passage of the Marihuana Tax Act of 1937. Cannabis was dropped from the U.S.P. in 1942 and as a result, legal penalties for possession of cannabis continued to increase throughout the 1950s. The passage of the U.S. Drug Enforcement Agency’s (DEA) Comprehensive Drug Abuse Prevention and Control Act of 1970 officially outlawed cannabis for any use (including medical) by classifying it as a Schedule I Controlled Substance (Bridgeman \& Abazia, 2017). 
As a Schedule I Controlled Substance, the cannabis plant has been defined as "having high potential for abuse, no currently accepted medicinal use in treatment in the United States, and a lack of accepted safety data for use of the treatment under medical supervision" (Bridgeman \& Abazia, 2017, p. 180). The plant contains at least 750 chemicals including over 104 different cannabinoids including dronabinol, also known at 9-tetrahydrocannabinol, or THC, cannabidiol (CBD), and cannabinol (CBN). Tetrahydrocannabinol (THC) is the primary psychoactive compound, while CBD is the non-psychoactive compound. Despite criminalization and legislative actions limiting use, research, and distribution, cannabis has continued to be the most cultivated, trafficked, and abused illicit drug worldwide (Madras, 2015).

Recent efforts to revive cannabis as a medicine have been driven by multiple factors, with the most prominent being the inability of current medical approaches and pharmaceuticals to provide symptom relieve to individuals suffering from debilitating chronic disease. Current cannabis consumption has reached an all-time high, with an annual prevalence rate of approximately 147 million individuals, or nearly $2.5 \%$ of the global population (Madras, 2015). The 2016 National Survey on Drug Use and Health results estimated 24.0 million Americans aged 12 years of age or older reported current cannabis use with 8.9 percent of the population aged 12 years or older reported use within the previous month. Not only has the percentage of people aged 12 years or older reporting current cannabis has increased from 2002 to 2015, but the increase in use among this younger age group is also greater than the increase in use reported by adult age groups 18 to 25, and 26 or older. (Substance Abuse and Mental Health Services Administration, 2017) 
Prevalence reports consistently demonstrate that cannabis use for both recreational and medicinal purposes continues to rise (Madras, 2015), while legislative actions, ballot measures, and public opinion polls also reflect increased societal acceptance of cannabis use, especially for medical purposes. For example, the 2016 Gallup poll on American's views on legalizing cannabis indicated that $60 \%$ of the population surveyed believed cannabis should be legalized. Despite continued controversies surrounding the legal, ethical, and social implications of cannabis, as of March 2020, 33 states, District of Columbia, Guam, Puerto Rico, and the U.S. Virgin Island have approved medical use and 14 states have approved the use of cannabis recreationally (NCSL, 2020).

\section{Federal and State Legislation through 2019}

Classification of cannabis as a Schedule I Controlled Substance both prohibits practitioners from prescribing cannabis and also prohibits research using cannabis, except for federally funded research under the oversight of the National Institute on Drug Abuse (U.S. Food and Drug Administration [FDA], 2019). Despite Drug Enforcement Administration (DEA) classification and federal law, individual states have instituted varying legal approaches to authorizing medical marijuana programs over the past few decades, with more recent efforts focusing on introducing federal bills in an effort to reschedule cannabis. In 2016, the Food and Drug Administration (FDA) requested a scientific and medical evaluation and scheduling recommendation from the Department of Health and Human Services (HHS). The report and recommendations concluded that marijuana has a high potential for abuse, has no currently accepted medical use in treatment in the United States, and lacks accepted safety for use under medical 
supervision (Drug Enforcement Administration [DEA], 2016); thus, the DEA denied petitions to reschedule cannabis as a Schedule II Controlled Substance. The DEA did, however, recognize the lack of scientific study on cannabis and announced a policy change which expanded the number of DEA-registered cannabis manufacturers to increase the supply of cannabis for FDA-authorized research. (The National Council of State Boards of Nursing [NCSBN], 2018)

In terms of state legislation, each jurisdiction's medical marijuana program, or MMP, is unique, with state-specific statues in place which differ in provisions regarding the process for procuring a certification for the use of cannabis, the amount of cannabis that can be distributed to an individual, legal protections, designation of caregivers, and health care provider responsibility. Medical marijuana programs also have differing qualifying conditions/diagnoses, disease states, or symptoms that enable a patient to obtain certification and register with the state as a medical marijuana patient. (NCSBN, 2018) There are 57 qualifying conditions included among the different jurisdictional laws, with the most common being: ALS; Alzheimer's disease; arthritis; cachexia; cancer; Chron's disease and other irritable bowel syndromes; epilepsy or seizure disorder; glaucoma; hepatitis C; HIV/AIDS; nausea; neuropathies; pain; Parkinson's disease; persistent muscle spasms (including multiple sclerosis); post-traumatic stress disorder; sickle cell disease; and terminal illness (Madras, 2015; NCSBN, 2018).

The National Conference of State Legislatures (NCSL, 2020) provides useful state-specific medical marijuana resources and guidelines for practitioners to become knowledgeable of their role. For example, as federal law prohibits practitioners from prescribing cannabis, some MMPs require an established and ongoing health care 
provider-patient relationship in order to certify, while others require just a consultation and written recommendation. A few MMPs allow advanced practice registered nurses (APRNs) to certify, but most only allow medical doctors (MDs), with some MMP programs requiring practitioners to undergo specific training in order to be a participating provider. Medical marijuana programs also have provisions for hospice providers, nursing, medical facilities, personal care attendants, or home health aides to act as a designated caregiver for the administration of medical marijuana to ill patients (NCSBN, 2018; NCSL, 2020).

\section{Use of Cannabis for Medical Purposes}

Currently, the U.S. FDA does not approve the application of the cannabis plant for the treatment of any disease or condition; however, one cannabis-derived and three cannabis-related drug products have been approved and are available with a prescription from a licensed healthcare provider. Epidiolex, which contains a purified form of CBD has been approved for the treatment of seizures, while Marinol and Syndros, which include the psychoactive ingredient THC, have been approved for use as an anti-emetic, appetite stimulant, multiple sclerosis treatment, and for spasticity, respectively. Cesamet, approved to treat severe nausea and vomiting caused by cancer drug treatment, contains the active ingredient nabilone, which is a synthetic chemical similar to THC. (Medscape, 2006; FDA, 2019).

Whiting and colleagues (2015) defined medical cannabis as the use of the unprocessed cannabis plant, not a prescription pharmaceutical, for medical therapy to treat disease or alleviate symptoms. In order to use cannabis for medical purposes, MMPs 
have established conditions which qualify a patient to use cannabis (NCSBN, 2018).

However, the NCSBN (2018) review revealed that such conditions have generally been included based on limited availability of clinical research, or because of symptoms they share with conditions better studied in the literature. For example, the more general qualifying conditions such as chronic pain, neuropathies, and nausea are the most researched symptoms associated with medical cannabis. Although research comparing the effects of cannabis against other standard medications do exist, clinical trials are small in number, with varying risk of bias. As a result, research has not been able to definitively specify indications, dosage, route, safety, adverse effects, and long-term effects of cannabis, let alone clinical guidelines for practitioners (NCSBN, 2018).

The most prominent and thorough reports and review of the medical cannabis literature have been conducted by the World Health Organization (WHO) (Madras, 2015), Whiting and colleagues (2015), and The National Academy of Sciences (2017). The WHO report does not provide a comprehensive review of the literature, but rather summarizes evidence of cannabis for medicinal use globally, citing sources from primary manuscripts and 10 meta-analyses. It highlights therapeutic indications and considerations for neurological diseases and symptoms, AIDS wasting, cachexia and appetite enhancement, cancer and cancer-related symptom management, Crohn's disease, Post-traumatic stress disorder (PTSD), and glaucoma (Madras, 2015).

The WHO report used an international survey by Hazekamp, Ware, Muller-Vahl, Abrams, and Grotenhermen (2013) to demonstrate the global use of medical cannabis. Respondents $(\mathrm{n}=953)$ from the United States, Germany, Canada, France, the Netherlands, and Spain were self-reported users of cannabis for medicinal purposes, 
generally male $(64 \%)$, and the mean age was 40.7 . This population reported using cannabis for back pain (11.9\%), sleeping disorders (6.9\%), depression $(6.7 \%)$, injury or accident-generated pain (6.2\%), and multiple sclerosis $(4.1 \%)$.

Whiting et al. (2015) published the highly regarded medical cannabis resource following a systematic review to determine the benefits and adverse events (AEs) of cannabis. A total of 79 randomized clinical trials $(6,462$ participants $)$ comparing cannabis with usual care, placebo, or no treatment for the following indications were included: nausea and vomiting due to chemotherapy; appetite stimulation in HIV/AIDS; chronic pain; spasticity due to multiple sclerosis or paraplegia; depression; anxiety disorder; sleep disorder; psychosis; glaucoma; or Tourette's syndrome. The main outcomes and measures were patient-relevant and disease-specific outcomes, activities of daily living, quality of life, global impression of change, and AEs. Common AEs reported included dizziness, dry mouth, nausea, fatigue, somnolence, euphoria, vomiting, disorientation, drowsiness, confusion, loss of balance, and hallucination. Study quality was assessed using the Cochrane risk of bias tool, all review stages were conducted independently by two reviewers, and data were pooled using random-effects meta-analysis.

Four trials (5\%) were judged at low risk of bias, 55 (70\%) high risk, and $20(25 \%)$ unclear risk; however, the major source of bias was determined to be incomplete outcome data, with more than 50 percent of trials reporting unacceptably high drop-out rates among cannabis-naïve subjects. Results demonstrated that most trials showed improvement in symptoms associated with cannabis use; however, the associations did not reach statistical significance in all trials. Compared with placebo, cannabis was associated with a greater average number of patients showing a complete nausea and 
vomiting response ( $47 \%$ vs. $20 \%$; odds ratio 3.82 [95\% Cl, $1.55-9.42] ; 3$ trials), reduction in pain ( $37 \%$ vs. $31 \%$; odds ratio 1.41 [95\% $\mathrm{Cl}, 0.99-2.00] ; 8$ trials), a greater average reduction in numerical rating scale pain assessment (on a 1-10-point scale; weighted mean difference -0.46 [ $95 \% \mathrm{Cl},-0.08$ to -0.11$]$; 6 trials), and average reduction in the Ashworth spasticity scale (weighted mean difference -0.12 [95\% Ci, -0.24 to 0.01 ]; 5 trials). Studies found an increased risk of short-term AEs with cannabis use, including dizziness, dry mouth, nausea, fatigue, somnolence, euphoria, vomiting, disorientation, drowsiness, confusion, loss of balance, and hallucination (Whiting et al., 2015). Whiting et al. concluded that moderate-quality evidence existed supporting the use of cannabis for the treatment of chronic pain and spasticity while low-quality evidence suggested that cannabis was associated with improvements in nausea and vomiting due to chemotherapy, weight gain in HIV infection, sleep disorders, and Tourette syndrome.

In the National Academies of Sciences, Engineering, and Medicine 2017 report, The Health Effects of Cannabis and Cannabinoids: The Current State of Evidence and Recommendations for Research, experts developed a standard language to categorize the weight of the evidence for cannabis used medicinally for specific health conditions. "Conclusive" evidence existed when strong evidence from randomized controlled trials, and/or many good-quality studies supported the conclusion that cannabis was an effective or ineffective treatment for the health condition. "Substantial" evidence existed when several supportive good-quality studies existed with very few or no credible opposing findings. "Moderate" evidence referred to the existence of "some" evidence but with identified limitations, such as chance, bias, and confounding factors, that could not be ruled out with reasonable confidence. "Limited" evidence was determined when there 
were supportive findings from fair-quality studies or mixed findings; a significant amount of uncertainty existed. Finally, "insufficient" evidence was reported when there were mixed findings, a single poor study, or no studies at all. (National Academies, 2017)

Conclusive or substantial evidence was determined for therapeutic use of cannabis for the treatment of chronic pain, as an antiemetic in the treatment of chemotherapyinduced nausea and vomiting, and in the improvement of patient-reported multiple sclerosis spasticity symptoms. (National Academies, 2017) Moderate evidence supported cannabis being effective for improving short-term sleep outcomes in individuals with sleep disturbances associated with obstructive sleep apnea syndrome, fibromyalgia, chronic pain, and multiple sclerosis (NCSBN, 2018). A greater amount of substantial evidence suggested adverse outcomes of cannabis such as the statistical association between cannabis smoking and worse respiratory symptoms, more frequent bronchitis, increased risk of motor vehicle crashes, lower birth weight of offspring, development of schizophrenia or other psychoses, and development of problematic cannabis use (National Academies, 2017).

A review of the literature searching all scholarly articles related to cannabis and its' derivatives and the qualifying conditions listed by jurisdiction through February of 2018 was completed by the NCSBN to inform the establishment of the National Nursing Guidelines for Medical Marijuana published in July 2018. Their review highlighted evidence that cannabinoids underperformed against standard first-lime medical treatments for pain, nausea, and cachexia, namely megestrol acetate, ondansetron, and dihydrocodeine respectively and showed effects comparable to tramadol and pregabalin. Cannabis was shown to carry its' own set of AEs, with one risk being that patients may 
forego effective standard medications in favor of cannabis. The review validated the moderate- to high-quality evidence supporting cannabis as an effective treatment for cachexia, chemotherapy-induced nausea and vomiting, pain, chronic pain, neuropathies, spasticity, reduction in seizure frequency, reduction in PTSD nightmares, and improvement in ticks. Other research by Fox et al. and Greenberg et al., both cited in NCSBN (2018), posited, however, that improvements in other symptomatology might be related to the more general effects of cannabis, including sedation, appetite stimulation and euphoria, which mask symptoms and increase a subjective sense of well-being leading to improved self-reported quality of life in study participants (NCSBN, 2018).

\section{Physiologic, Therapeutic, and Adverse Effects of Cannabis}

The endocannabinoid system. Although the cannabinoid signaling system is ancient, existing in invertebrates and advanced vertebrate organisms (Madras, 2015), the discovery of how cannabis interacts with the body has been a slow one. The brain's opiate receptor was identified in 1973, but it wasn't until 1988 that a government-funded study by Allyn Howlett and William Devane determined not only that the mammalian brain has receptor sites that respond to compounds found in cannabis, but also that these receptors are the most abundant type of neurotransmitter receptor in the brain (Moore, 2018).

Over the last 25 years, the endocannabinoid system (ECS) has emerged as an important neuromodulatory system that plays an important role in central nervous system (CNS) development, synaptic plasticity, and the response to endogenous and environmental insults (Lu \& Mackie, 2016). The ECS has four main components: G 
protein-coupled cannabinoid $\mathrm{CB} 1$ and $\mathrm{CB} 2$ receptors; endogenous endocannabinoids, or lipids, produced by the body which target these receptors (five endocannabinoids have been identified as compared to over 100 detected in the cannabis plant (Grotenhermen, 2004); enzymes that catalyze or break down endocannabinoids for use by the body; and mechanisms involved in synaptic and cell messaging (Lu \& Mackie, 2016; Madras, 2015)

Function of the endocannabinoid system. Endocannabinoids play a fundamental role in regulating pleasure, memory, thinking, concentration, body movement, awareness of time, appetite, pain, sensory processing, and brain development (Madras, 2015). In the brain and CNS, endocannabinoid signaling controls excitatory and inhibitory synaptic transmission and regulatory functions in the brain through many intricate mechanisms. This signaling guides neural stem cell survival and proliferation, modulates the extent of brain damage resulting from mechanical, blood flow, or other forms of injury, and coordinates sensory input, which in turn regulates neurogenesis, appetite, nausea, sleep, neurotransmitters, seizure activity, motor function, and cognitive function (Kumar, Chambers, \& Pertwee, 2001; Madras, 2015).

In peripheral tissues, endocannabinoid signaling accounts for effects throughout the intestinal mucosa such as inhibition of gastrointestinal motility and gastric emptying. Increased cardiac output, myocardial oxygen requirement, and tachycardia commonly result from endocannabinoid activation inhibiting the vagal nerve (Grotenhermen, 2004). Other peripheral effects of cannabinoids include increased liver cell metabolism; increased activity of immune cells; increased energy metabolism in muscle cells and the formation of new muscle fibers; regulation of critical stages of pregnancy and the 
preservation of normal sperm function; and perhaps respiratory urinary system function (Kumar et al., 2001; Madras, 2015).

Pharmacology. The effects of endocannabinoids are primarily mediated by CB1 and $\mathrm{CB} 2$ receptors. $\mathrm{CB} 1$ receptors are abundant in the CNS, particularly on axon and preterminal axon segments in the cerebellum, hippocampus, cortex, and basal ganglia. Activation of these CNS receptors is responsible for the effects of cannabinoids on cognition, coordination, learning and memory, cognitive function, executive function and control, integration of sensory input, motor control, and planning (Lu \& Mackie, 2016; Madras, 2015). CB1 receptors have also been found in the central striatum responsible for prediction and the feeling of reward, the amygdala responsible for feelings of anxiety, emotion, and fear, the hypothalamus controlling appetite, hormone levels, and sexual behavior, and the brain stem and spinal cord which control vomiting and pain perception. $\mathrm{CB} 2$ receptors are expressed at much lower levels in the CNS and are primarily present in microglia which are the macrophages that act as the primary immune system of the brain and spinal cord. These receptors are also found in vascular tissue, on immune cells, and within the hematopoietic system which consists of bone marrow, spleen, thymus and lymph nodes. (Lu \& Mackie, 2016; Madras, 2015) In addition to CB1 and CB2 receptors, several other receptor subtypes have been reported to interact with cannabinoids (Zou \& Kumar, 2018).

The mechanism of action of cannabinoids has been established mainly based on THC's agonistic action at the cannabinoid receptors (Grotenhermen, 2004). Increased interest in cannabidiol (CBD) and its' unique therapeutic uses has led to ongoing investigation into its mechanism of action. Unlike THC, CBD does not activate CB1 and 
$\mathrm{CB} 2$ receptors, which accounts for its lack of psychotropic activity. Cannabidiol has been found to potentiate some of THC's beneficial effects as it reduces THC's psychoactivity, thus allowing patients to tolerate higher, more therapeutic doses of THC. Besides its effect on THC, CBD has been called a "multi-target" drug as it interacts with numerous other non-endocannabinoid signaling system receptors such as G-protein-coupled receptors, 5-HT1a receptor, and alpha 3 and alpha 1 glycine receptors for example. CBD's activation of multiple targets contributes to its many properties ranging from analgesic, anti-inflammatory, antioxidant, anti-spasmodic, and anti-epileptic. (Devinsky et al., 2014)

Pharmacokinetics. The pharmacokinetics of cannabis, or the absorption, distribution, metabolism, and elimination of any drug is highly variable based on the route of administration. Inhaled drugs enter the lungs and cross into the bloodstream at a rate similar to if the drug was injected intravenously. Drugs taken orally, however, are absorbed mainly through the small intestine but are subject to liver metabolism and gastrointestinal (GI) variables such as drug-food interaction, drug-drug interaction, and GI health (Whalen, 2019). The three most common methods of cannabis administration are inhalation via smoking, inhalation via vaporization, and ingestion of edible products (Bridgeman \& Abazia, 2017). Cannabis comes in other forms such as pills, oil, topical ointments and creams, liquid drinks, and suppositories. Method of administration impacts the onset, intensity, duration of effect, as well as the effect on organ systems, addictive potential and negative consequences associated with use (Bridgeman \& Abazia, 2017; Madras, 2015). Thus, cannabinoid pharmacokinetic research has been challenging. 
Tetrahydrocannabinol and other cannabinoids are rapidly absorbed after inhalation or intravenous administration with maximum brain concentration being reached within 15 minutes (Bridgeman \& Abazia, 2017). Maximum psychological and physiological effects reach a plateau lasting two to four hours before slowly declining. The amount absorbed varies between 20 and $45 \%$ of the THC content. When taken orally, THC undergoes variable absorption depending on GI variables and has been shown to have a narrower therapeutic window. Blood concentrations following oral consumption have been shown to reach only $25-30 \%$ of those obtained by smoking the same dose. Due to GI variables, onset of effect is also delayed 30 minutes to 2 hours following oral consumption, with the duration of effect lasting five to six hours and psychomotor and cognitive effects persisting much longer. is prolonged due to slow absorption from the gut. (Bridgeman \& Abazia, 2017) Cannabinoids do cross the placenta, enter fetal circulation, penetrate breast milk, and accumulate in fatty tissues and thus elimination from the body is very slow. Cannabinoids are metabolized by the liver, contributing to large individual differences in rates of metabolism. (Bridgeman, 2017; Kumar et al., 2001)

Adverse effects and safety considerations. The effects of cannabinoid consumption are euphoria and relaxation, perceptual alteration, time distortion and the intensification of normal sensory experiences. Short-term memory and attention, motor skills, reaction time and skilled activities are impaired with impairments being dosedependent and potentiated with concomitant alcohol intake. Anxiety and panic reaction are common and effects on the cardiovascular system include tachycardia with heart rate increases of $20-50 \%$ within a few minutes lasting for up to 3 hours. Blood pressure tends 
to decrease when standing but not when sitting (Bridgeman \& Abazia, 2017; Kumar et al., 2001). The lethal dose of oral THC has been established in rats; however, no cases of death due to toxicity following the maximum oral THC dose in dogs and monkeys occurred (Grotenhermen, 2004). Acute fatal cases in humans have not been substantiated to-date and long-term, large sample size studies have failed to show an increase in cardiovascular mortality related to cannabis use (Frost, Mostofsky, Rosenbloom, Mukamal, \& Mittleman, 2013; Mukamal, Maclure, Muller, \& Mittleman, 2008; Sidney, Beck, Tekawa, Quesenberry, \& Friedman, 1997). As THC is known to cause tachycardia and increased cardiac output, its use may be associated with increased mortality in patients with a history of myocardial infarction or increased risk of precipitating an acute coronary event in susceptible patients (Kattoor \& Mehta, 2016)

Isolated cannabinoids have undergone a number of randomized controlled trials (RCTs) documenting safety, efficacy, and side effect profiles in order to formalize the drug approval process for the three current pharmaceuticals including Marinol, Syndros, and Epidiolex (FDA, 2019). Few RCTs are reported for whole plant cannabis and the majority of trials have several limitations so the safety of cannabis cannot be assured at this time without key information. (Madras, 2015; National Institute on Drug Abuse [NIDA], 2019; Whiting et al., 2015)

A systematic review by Wang, Collet, Shapiro, and Ware (2008) evaluated a total of 31 studies $(\mathrm{N}=3,122)$ including 23 RCTs examining the use of medical cannabinoids and AEs. A total of 4,779 AEs were reported; $96.6 \%$ or 4,615 were not deemed by the authors to be serious. The most common serious AEs included relapsing MS $(9.1 \% ; 15$ events), vomiting $(9.8 \% ; 16$ events), and urinary tract infections $(9.1 \% ; 15$ events). 
Interestingly, no significant differences in the rates of serious adverse events between individuals receiving medical cannabis and controls were identified (relative risk, 1.04; 95\% CI, 0.78-1.39). The most commonly reported non-serious adverse event was dizziness, with an occurrence rate of $15.5 \%$ (714 events). Other negative adverse effects reported with acute cannabis use included hyperemesis syndrome, impaired coordination and performance, anxiety, suicidal ideations or tendencies, and psychotic symptoms. Chronic effects included mood disturbances, exacerbation of psychotic disorders, cannabis use disorders, withdrawal syndrome, and neurocognitive impairments, as well as cardiovascular and respiratory conditions (Wang et al., 2008).

Drug interactions may exist between cannabis and other pharmaceuticals especially since hepatic cytochrome 450 (CYP 450) isoenzymes 2C9 and 3A4 play a significant role in the primary metabolism of THC and CBDA, whereas 2C19 and 3A4 may be responsible for metabolism of CBD. Limited clinical trials have sought to quantify this effect, but drug information data available on the two current cannabinoid pharmaceuticals--Marinol and Syndros--reported altered THC and CBD levels with concomitant administration of ketoconazole and rifampin. Additionally, smoking cannabis may increase theophylline metabolism as is also seen after smoking tobacco (Bridgeman \& Abazia, 2017).

Cannabis and central nervous system impairment. The growing use of cannabis worldwide has led to more recent increases in the number of human studies, especially related to concerns of harmful effects. Neuroimaging techniques are being used to determine the effects of cannabis on brain structure and function (Batalla et al., 2013). Cognitive functions such as attention, concentration, decision-making, impulse control, 
reaction time, verbal fluency, and working memory had previously demonstrated inconsistent acute impairment in a dose-dependent manner (Crean, Crane, \& Mason, 2011). Several cognitive functions had also been shown to be impaired in recently abstinent cannabis users for seven hours up to 20 days. Following sustained abstinence in chronic, daily cannabis users, impairment in cognitive functioning continued for several months with decision-making, planning, and concept formation being the most prominent and durable deficits (Madras, 2015; Wadsworth, Moss, Simpson, and Smith, 2006).

A recent literature review by Mandelbaum and Monte (2017) reported the existence of "strong evidence" that chronic cannabis abuse causes cognitive impairment and physical damage to the brain, particularly white matter, theorized to be due to the high saturation of CB1 receptors in that area. Similarly, Nader and Sanchez (2018) systematically reviewed 13 neuropsychological studies addressing a variety of cognitive domains, 25 structural neuroimaging studies, and 18 functional neuroimaging studies comparing a group of regular cannabis users with a group of controls consisting of nonusers or individuals with very limited drug experience. Important findings confirmed the most frequently affected cognitive domains to be executive functioning, memory, attention, and learning. Evidence existed among thirteen studies reviewed that cognitive impairment is reversible with scores on neuropsychological test battery (Halstead-Reitan Battery) administered to cannabis users and control group demonstrating "virtually no differences between the groups" (Nader \& Sanchez, 2018, pg. 11). However other studies such as one conducted by Meier et al. (2012) showed that those who initiating cannabis use before the age of 18 resulted in persistent impairment following one year or more of sustained abstinence. 
Nader and Sanchez's (2018) systematic review of 22 structural neuroimaging studies also confirmed the link between brain structure and connectivity. Findings determined that whole brain volume was not affected by cannabis use, but that CB1-rich areas such as the amygdala and hippocampus showed structural alterations. Functional neuroimaging studies also revealed altered patterns of brain activities in cannabis users, possibly due to upregulation of $\mathrm{CB} 1$ receptors. They concluded that the implications of the structural and functional findings as a result of cannabis use are yet to be determined, but added that even small impairment in cognitive functioning should be concerning.

Harmful effects to peripheral tissues. Chronic cannabis use has been associated with an increased prevalence of symptoms of chronic bronchitis, inflammation to central airways, and increased rates of respiratory infections and pneumonia comparable to that of smokers of tobacco. Cannabis use has not been associated with adverse effects on pulmonary function testing nor does it appear to contribute to chronic obstructive pulmonary disease nor are its' carcinogenic effects clear at the present times. Use has been associated with increased risk of myocardial infarction (MI), stroke, and transient ischemic attaches (TIA) during cannabis intoxication (Madras, 2015).

Carcinogenic potential. There is currently no consensus on whether cannabis use is associated with overall cancer risk; however, cannabis smoke contains several of the same carcinogens as tobacco smoke at up to $50 \%$ higher concentrations with three times the tar per cigarette. In vitro and in vivo evidence has demonstrated pre-neoplastic histological and molecular changes to respiratory mucosa exposed to chronic cannabis smoke (Madras, 2015). A 2015 systematic review identified four cohort studies and 30 case-control studies investigating cannabis use and cancer risk: 11 studies on upper 
digestive cancers, six studies on lung cancer, three studies on testicular germ cell tumors, six studies on childhood cancers, one study on all cancers, one study on anal cancer, one study on penile cancer, two studies on non-Hodgkin lymphoma, one study on malignant primary gliomas, one study on bladder cancer, and one study on Kaposi sarcoma (Huang et al., 2015). The largest number of studies investigating the impact of cannabis and cancer involve head and neck cancer. Pooled analyses reported no overall association for head and neck cancer but a possible increased risk with dose response for oropharyngeal cancer and a decreased risk for tongue cancers (Huang et al., 2015). Studies identifying dosage and use found that even "highest exposure categories" rarely exceeded 10 jointyears of cumulative lifetime use which would translate into only 0.5 pack-years of cigarette smoking. Thus, the smaller amounts of cannabis that are regularly smoked compared with tobacco was suggested to explain the null association of cannabis with lung cancer. The authors also discussed the tumor-suppressant effect of THC and other cannabinoids which could possibly counteract the tumor-promoting effects of the carcinogens. For the other cancers, the review concluded that there was still insufficient data to make any conclusions whether an association existed between cancer and cannabis use (Huang et al., 2015).

A more recent meta-analysis by Park and Myung (2018) also looked at lung cancer. The analysis which included a total of 13,646 cancer patients and 151,572 participants without cancer. Results showed a marginally statistically significant association between cannabis smoking and risk of lung cancer $(\mathrm{OR}=1.76,95 \% \mathrm{CI} 1.00$ 3.08). Subgroup analysis also showed an increase risk of testicular cancer when the duration of cannabis smoking exceeded 10 years $(\mathrm{OR}=1.50 ; 95 \% \mathrm{CI}, 1.02-2.09)$. Thus, as 
cannabis use rates continue to increase, well-designed, large-scale studies are necessary to best determine the potential risks conferred by its use (Huang et al., 2015).

Cannabis during development. Accumulating evidence suggests that prenatal exposure may interfere with normal development and maturation of the brain as children exposed to cannabis in utero demonstrate impaired attention, learning, memory, impulsivity, behavioral problems, and higher likelihood of using cannabis when they mature (Sonon, Richardson, Cornelius, Kim, \& Day, 2015). Regular, heavy cannabis use during adolescence has been associated with cognitive deficits, impaired attention, learning, memory, and IQ reduction. Brain imaging has also revealed changes in adolescents or adults who initiated cannabis during adolescence such as smaller whole brain and hippocampus, reduced cortical grey matter and insular cortical thickness associated with level of use. Findings have obvious implications for education and also have been associated with lower income level, lower college degree completion, greater need for economic assistance, unemployment, and use of other drugs. (Madras, 2015; Osuch et al., 2016).

Cannabis and society. In addition to the above, cannabis use continues to present a widespread and serious personal and public health problem (Stinson, Ruan, Pickering, \& Grant, 2016). As cannabis use rises, an increasing burden on emergency services documenting cannabis use alone or in combination with other drugs has increased. A nationwide study by Dr. He Zhu and Dr. Li-Tzy Wu (2016) of Duke University Medical Center showed that across the United States, between 2004 and 2011, emergency department visits involving the use of cannabis increased from 51 to 73 per 100,000 
patients with those involving cannabis combined with other drugs also increased from 63 to 100 per 100,000 .

Cannabis consumption impairs driving ability and confers a higher risk for motor vehicle accidents. The effects of cannabis on cognition also affect work, employment, performance, and everyday life, potentially increasing unemployment among users. Cannabis for medical use has recently created dilemmas for the workplace, as ensuring safety of workers who are under the influence or who recently consumed cannabis is not possible (Madras, 2015).

Dependence, abuse, and cannabis use disorder (CUD). Classifying cannabis use in the U.S. is dictated by the Diagnostic and Statistical Manual of Mental Disorders (DSM-V) (2013). The World Health Organization's (2019) International Statistical Classification of Diseases and Related Health Problems (11th ed.; ICD-11) and DSM-V have designated that cannabis is addictive and currently recognizes cannabis-related dependence disorders. Generally, the effects of cannabis use can be understood as acute and chronic. The acute phase includes intoxication and withdrawal states, along with secondary complications: delirium; psychosis; anxiety; and insomnia. Chronic regular use can be characterized by disordered behavior (APA, 2013; WHO, 2019).

Depending on the setting (i.e., Emergency Department, office visit, or rehabilitation program), different effects of cannabis may be the focus and the diagnostic criteria of the varying effects can be defined as: cannabis intoxication; cannabis withdrawal; cannabis intoxication delirium; cannabis-induced psychotic disorder; cannabis-induced anxiety disorder; cannabis-induced sleep disorder (APA, 2013). 
According to the latest World Drug Report published June of 2019 by the United Nations Office on Drugs and Crime (UNODC), approximately 35 million people are estimated to suffer from drug use disorders requiring treatment services. Approximately 13.1 million people globally are psychologically or physiologically dependent on cannabis based on 2017 estimates by UNODC. Data from the US indicates that the prevalence of cannabis use increases when perceived risk of use decreases. Perception of risk has declined in the face of changing legal status of the drug, which researchers claim has resulted in the rise in daily use among youth (Miech, Johnston, \& O’Malley, 2017).

As a consequence of increased use, it comes as no surprise that the rate of reported CUD in the US has climbed significantly (Madras, 2015).

\section{Implications for Advanced Practice Nursing Education}

As the use of both medical and recreational cannabis continues to rise, the fields of public health, science, and education, as well as healthcare providers, must adjust to support the needs of the population. Advanced practice registered nurses (APRNs), including nurse practitioners, clinical nurse specialists, nurse anesthetists, and nurse midwives, play a pivotal role in the future of health care and are increasingly the primary care providers at the forefront of providing services to the public (ANA, 2018). The landmark document Consensus Model for APRN Regulation: Licensure, Accreditation, Certification, and Education (NCSBN, 2008) delineates APRN roles and provides recommendations about APRN licensure, accreditation, certification, and education. According to the Consensus Model, APRNS must complete an accredited master's or doctorate program. 
APRN education. The American Nurses Association and Nurse Practice Acts outline that APRNs must have sufficient depth and breadth of clinical experience as RNs, and APRN education must build on their RN competencies. They must be prepared to assume responsibility for health promotion and maintenance as well as assessment, diagnosis, and management of patient problems, including the use and prescription of nonpharmacologic ad pharmacologic interventions (ANA, 2018). Current APRN programs require students to complete the "3 Ps": advanced pharmacology; advanced pathophysiology; and advanced physical health assessment. These foundational courses require the maturation of foundational knowledge as well as the development of advanced critical-thinking skills. Advanced practice registered nurses must meet clinical competencies which are defined by patient-care needs, not practice setting, and must maintain national certification and practice with a significant focus on direct patient care (ANA, 2018).

Knowledge gaps. As awareness of and interest in the use of medical cannabis has increased, it has become clear that health care professionals need to be involved in management decisions but often feel unprepared and lacking in knowledge and education necessary to engage in informed discussions with patients. Needs assessment surveys have been used, mostly among physicians, to identify and rank the most common factors involved in decision making about using cannabis for therapeutic purposes (Ziemianski et al., 2015). Canada's national program for access to medical cannabis began in 2001; however, changes to the regulations which came into effect in August of 2016 allow nurse practitioners (NPs) to authorize eligible patients access to medical cannabis certification. This expansion in the NPs' scope of practice prompted a national online 
survey of NPs to assess knowledge and practice gaps related to medical cannabis, with the goal of informing the development of future education resources that increase clinical competence and improve patient care related to medical cannabis (Balneave, Alraja, Ziemianski, McCuaig \& Ware, 2018).

The national online survey of NPs was adapted from the national survey developed and used by Ziemianski et al. (2015). The survey consisted of six sections and assessed current and desired level of medical cannabis knowledge, desire for medical cannabis education, clinical experience related to medical cannabis, clinical barriers to prescribing and providing care related to medical cannabis, attitudes regarding which health care providers should be allowed to authorize medical cannabis use, and preferred formal for future medical cannabis education (Balneave et al., 2018; Ziemianski et al., 2015).

In 2013, there were 3,655 NPs eligible to practice in Canada. A convenience sample of 552 NPs were recruited through email lists of nursing organizations, of which 227 accessed the national survey and $182(33 \%)$ provided complete data for analysis. Descriptive statistics summarized respondents' demographic information, knowledge, experiences, barriers, attitudes, and preference for educational approaches. Perceived knowledge gap was calculated by computing the difference between individuals' current and desired knowledge level (i.e., only response pairs were used) (Balneave et al., 2018).

Results of the study demonstrated that respondents were most knowledgeable about the potential uses $(2.57 / 5.0)$ and risks $(2.39 / 5.0)$ of medical cannabis as well as the safety, warning signs, and precautions associated with medical cannabis use (2.21/5.0). 
The lowest mean knowledge level was for dosing and creating effective treatment plans $(1.63 / 5.0)$, similarities and differences across cannabis products $(1.83 / 5.0)$, and the current federal medical cannabis regulations (1.88/5.0) (Balneave et al., 2018).

Similar gaps in perceived knowledge and perceived needs concerning medical cannabis have been identified by physicians, with the largest gaps between current and desired knowledge concerning dosing, the development of treatment plans, and comparisons between cannabis and existing prescription cannabinoids. There was an expressed need for better knowledge of the risks and benefits of medical cannabis, with respondents reporting that their comfort level in including medical cannabis in their practice would increase with added education focusing on literature reviews, online, and small group continuing medical education activities (Ziemianski et al., 2015).

Cannabis education in APRN nursing programs. Although recommending medical cannabis is currently within the APRN scope of practice in US jurisdictions in which the use of cannabis is legal for medical purposes, the majority of patient certifications and recommendations have come from medical doctors (MD). Advanced Practice Registered Nurses remain responsible for maintaining or seeking knowledge and clinical competency related to patient care needs and clinical practice. Cannabis classification as a Schedule I controlled substance has limited research and empirical evidence supporting its effectiveness, and in turn medical and nursing education, has lacked instruction related to the pharmacology, physiologic effects, uses, neurological symptoms, drug-to-drug interactions, and adverse effects of cannabis. With the current and projected prevalence of cannabis use by patients, it is clear that the addition of curriculum content to provide APRNs with principles of safe and knowledgeable practice 
is warranted. In order for APRNs to continue ensure safe and appropriate patient care, cannabis-specific curriculum content providing knowledge related to the current state of legalization for medical and recreational use, the endocannabinoid system, pharmacology, current research, and most importantly, safety considerations for the patient using cannabis is necessary (NCSBN, 2018).

National Council of State Boards of Nursing (NCSBN) Guidelines. Sweeping changes in societal attitudes towards cannabis, and the increasing use and legalization of medical and recreational cannabis, prompted the National Council of State Boards of Nursing (NCSBN) in 2017 to appoint members to a NCSBN Marijuana Regulatory Guidelines Committee. Recognizing that nurses were unsure of their responsibilities in the care of patients who may use cannabis, the committee was charged with exploring the trends and issues related to cannabis use and nursing regulation in order to develop model guidelines for APRNs care of patients. Committee findings prompted recommendations for addition of curriculum content and the formation of model guidelines in the event APRNs are to be able to provide certification of a qualifying condition under state requirements (NCSBN, 2018).

An in-depth review of current scientific literature also included the greater multitude of grey literature, or materials and research produced by organizations outside of traditional academic publishing and distribution channels. The committee consulted with known experts in the area of medical marijuana, its' use, safety, and legislation. Prelicensure graduate-level education programs, as well as online educational content and other information available to nurses, was surveyed and found to be significantly lacking in providing knowledge for how to care for patients using cannabis (NCSBN, 2018). 
The NCSBN review not only further highlighted the need for APRNs to have practical information to care for the increasing number of patients utilizing cannabis, it also established recommendations for APRN curriculum content as part of its national nursing guidelines for medical marijuana. Recommendations included the APRN student have a working knowledge of the current state of legalization, a working knowledge of the principles of an MMP, an understanding of the endocannabinoid system, cannabinoid receptors, cannabinoids, and the interactions between them, an understanding of cannabis pharmacology and the research associated with the medical use of cannabis, the ability to recognize signs and symptoms of cannabis use disorder and cannabis withdrawal syndrome, the ability to identify the safety considerations for patients using cannabis, and knowledge of administration and ethical considerations (NCSBN, 2018).

Next, the theoretical framework that will guide this study will be reviewed. 


\section{Theoretical Framework}

The Logic Model, developed by the W.K. Kellogg Foundation (2004), is a beneficial tool that facilitates effective program planning, implementation, and evaluation. A Logic Model is a systematic and visual way to develop a clear program strategy based on the program's desired results. A shared understanding of program goals, activities, and intended outcomes is necessary to engage others and clearly relay how a program will solve a particular problem.

The overarching purpose of the Logic Model is to serve as a visual road map, connecting the purpose of the planned program with the program's desired results. The Logic Model serves as a program design and planning tool to better organize program concepts, relationships, and structure. At the program implementation level, the Logic Model helps identify and collect data needed for ongoing monitoring and improvement, and as the model pictorially presents the components of the program, it clearly informs progress towards goals and program evaluation (Schmitz \& Parsons, 1999; W.K. Kellogg, 2004).

The Basic Logic Model (Figure 1) includes five components: resources; program activities; outputs; outcomes; and impact. Resources include the human, financial, organizational, and community resources a program has available to accomplish the activities. The program activities are processes, tools, events, actions, and interventions used to address the problem the program seeks to change. Outputs are the direct products

of the program activities, or the evidence that the program has been delivered. Outcomes can be both short and long-term and include specific changes expected at the individual or program participant level resulting from the program, while impact is the long-term 
intended or unintended change occurring at the organizational, community, or systems level as a result of the program. (Shakman \& Rodriguez, 2015; W.K. Kellogg, 2004)

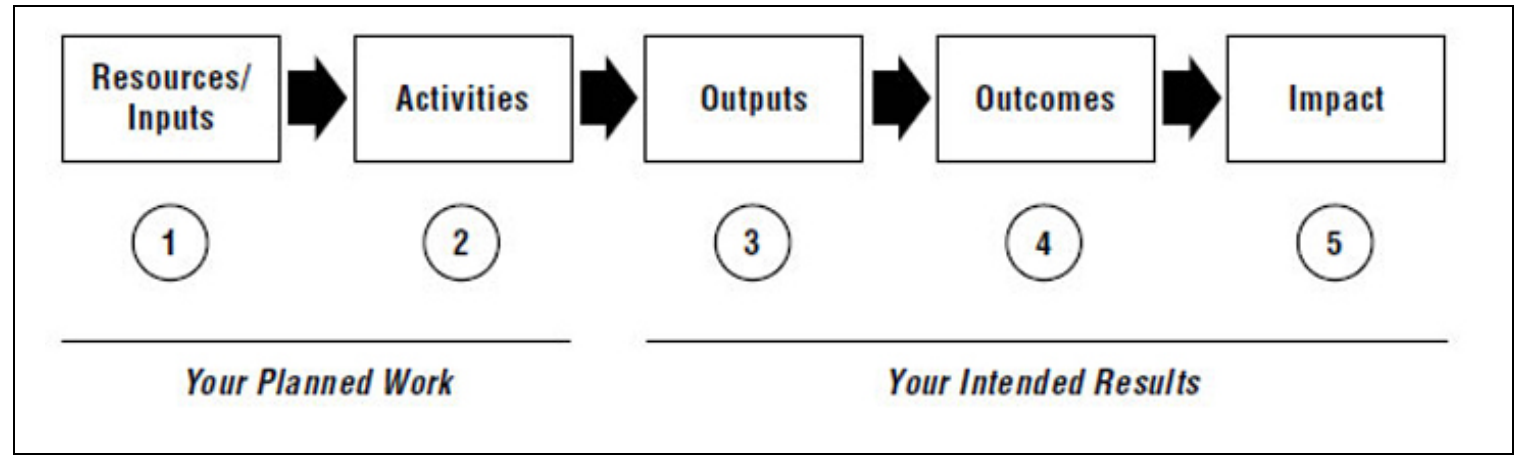

Figure 1. The Basic Logic Model

Next, the method will be presented. 


\section{Method}

\section{Purpose}

The purpose of the project was to evaluate the impact of a teaching module intended to provide essential knowledge and clinical implications of medical cannabis for the APRN student.

\section{Design}

This program development project included a pre-test, intervention, post-test design. The pre-test, or pre-video survey, was used to determine perceived current level of knowledge of medical cannabis among APRN student participants. The intervention, an educational video was developed to educate APRN students on essential knowledge for medical cannabis. A post-video survey was administered after student completion of the educational video to measure improved knowledge.

\section{Sample and Site}

Advanced practice registered nurse students at Rhode Island College, School of Nursing (RIC SON), enrolled in Fall 2019 and Spring 2020 Nursing 505 Advanced Pharmacology, as well as Spring 2020 Nursing 620 were asked to participate in the study. The IRB approved informational letter, pre-video survey, and post-video survey were handed out prior to the start of class and the link to the educational video to be found online was given to students. The educational video consisted of a narrated PowerPoint presentation uploaded to YouTube.

\section{The Logic Model Framework}

Resources/Inputs. Collaboration with Nursing 505 and 620 faculty confirmed the absence of medical cannabis knowledge within the current curriculum. Advanced practice registered nurse students enrolled in Nursing 505 and 620 were the targeted 
group receiving the educational video. The program developer collaborated with course faculty to integrate the video into course curriculum. Clinical guidelines from the National Council of State Boards of Nursing (NCSBN) National Nursing Guidelines for Medical Marijuana (2018) were used to guide the content of the educational video. The program developer collaborated with APRNs from the NCSBN Regulatory Implications of Legal Cannabis Committee, who developed the guidelines, to review program content and assist as experts on this topic.

Activities/Procedures. The project proposal was accepted by the RIC IRB for review. The program developer completed the educational video. In collaboration with NURS 505 and 620 faculty, a date was selected for introduction of the study immediately before class. The program developer discussed the purpose of the study--to provide the APRN student with essential knowledge and clinical implications related to medical cannabis--and intended goals were discussed. Students were informed that the educational video was a required assignment, however completion of the pre- and postvideo survey was voluntary and anonymous. The educational video was a 30-minute narrated PowerPoint presentation which students were given the link to access online. A numbered pre- and post-video survey packet was handed out to students in class. The IRB approved informational letter explaining the purpose of the study as well as instructions for completing the pre-video survey followed by viewing the educational video, and the completing the post-video survey was also within this packet. Dates for completion of the pre-video survey, educational video, and post-video survey were assigned. Students were given two weeks to return the pre-video survey, two weeks to view the educational video, and two weeks to return the post-video survey. An email was 
sent to all enrolled students three days prior to classes when surveys were due reminding them to bring their returned survey to class. An email was sent reminding them to view the educational video three days before the due date. Surveys were anonymous and results confidential. Completed survey packets were returned by students immediately before class or during class break to a manila folder and the program developer was available to pick the folder up following class the two weeks the pre- and post-video surveys were due.

Activities/Program Development. An educational video geared toward APRN students based on recommended essential knowledge for medical cannabis (NCSBN, 2018) was developed. Content included: overview of current state of legalization of medical and recreational cannabis; principles of a medical marijuana program (MMP); endocannabinoid system; cannabis pharmacology and the research associated with the medical use of cannabis; signs and symptoms of cannabis use disorder and cannabis withdrawal syndrome; and safety considerations for patient use of cannabis. Content was generated directly from NCSBN guidelines described in Table 1. Prior to implementation, the program developer submitted the presentation to NCSBN advanced practice nurse collaborator for review and clarity of content. 


\section{Table 1}

Essential Knowledge Elements of APRN Student Educational Module

\begin{tabular}{|c|c|}
\hline $\begin{array}{l}\text { Purpose of Educational Module and } \\
\text { NCSBN Guidelines }\end{array}$ & \\
\hline Definitions & $\begin{array}{l}\text { Cannabis; Cannabidiol (CBD); } \\
\text { Cannabinoid; Tetrahydrocannabinol } \\
\text { (THC); Medical Marijuana Program } \\
(M M P)\end{array}$ \\
\hline Current State of Legalization & $\begin{array}{l}\text { DEA; Schedule I Controlled Substance } \\
\text { categorization, MMPS }\end{array}$ \\
\hline Principles of an MMP & $\begin{array}{l}\text { Department of Health statues; Health } \\
\text { care provider responsibilities; Certifying; } \\
\text { Qualifying conditions; APRN role }\end{array}$ \\
\hline The Endocannabinoid System (ECS) & $\begin{array}{l}\text { Discovery of ECS; Overview; Purpose; } \\
\text { Cannabinoid receptors; Enzymes; THC, } \\
C B D, \text { and } C B N\end{array}$ \\
\hline Cannabis Pharmacology and Research & $\begin{array}{l}\text { Current scientific evidence; Levels of } \\
\text { evidence; Indications supported by } \\
\text { evidence; Adverse effects; Routes of } \\
\text { administration; Risks to particular groups } \\
\text { of patients }\end{array}$ \\
\hline Clinical Encounter Considerations & $\begin{array}{l}\text { Signs and symptoms of cannabis adverse } \\
\text { effects; Identification of safety } \\
\text { considerations; Cannabis Use Disorder } \\
\text { (CUD) }\end{array}$ \\
\hline $\begin{array}{l}\text { Medical Cannabis Administration } \\
\text { Considerations }\end{array}$ & $\begin{array}{l}\text { Hospitalized patient considerations; } \\
\text { FDA-approved synthetic THC } \\
\text { medications; Providers as MMP- } \\
\text { designated caregivers }\end{array}$ \\
\hline Ethical Considerations & Patient care without judgement \\
\hline
\end{tabular}

The educational video was tailored to meet the scheduling needs of both the students and the course, and included a 30-minute, narrated PowerPoint presentation that students had two weeks to complete. For ease of access, the educational video was uploaded to YouTube and the students were given the link to view the video. As a course 
assignment, the educational video did not interfere with the current course curriculum or in-class time.

Outputs/Measurement. The goal was to have all APRN students enrolled in Fall 2019 Nurs 505, Spring 2020 Nurs 505, and Spring 2020 Nurs 620 complete the educational video as well as the pre- and post-video survey. The pre- and post-video surveys were identical and consisted of nine knowledge items (see Appendix A). The concept of the knowledge survey was taken from a national needs-based survey developed and piloted by Canadian researchers Ziemianski et al. (2015). The entire survey by Ziemianski et al. consisted of six sections-- knowledge, experience, barriers, attitudes, educational opportunities, and demographics--with varying numbers of items. For the purpose of this study, the pre- and post-video survey only consisted of a knowledge section.

The nine knowledge items from Ziemianski et al.'s survey prompted respondents to rank their perceived current level of knowledge on nine medical marijuana-related topics (see Table 2) using a 5-point Likert scale (1: very poor; 2: somewhat poor; 3: undecided; 4: somewhat good; and 5: very good). The nine items were utilized to identify Canadian physician's perceived knowledge gaps and perceived needs concerning cannabis for therapeutic purposes. The concept of Ziemianski, et al.'s survey was combined with NCSBN (2018) recommended essential knowledge elements for medical marijuana education in APRN nursing programs found in Table 1. Knowledge areas evaluated are listed in Table 2 on the next page. 


\section{Table 2}

\section{Knowledge Areas Evaluated}

\section{Knowledge area}

Current state of legalization of medical and recreational cannabis use.

Principles of a Medical Marijuana Program (MMP).

The endocannabinoid system, cannabinoid receptors, cannabinoids, and the interactions between them.

Cannabis pharmacology and research associated with the medical use of cannabis.

Signs and symptoms of cannabis use disorder and cannabis withdrawal syndrome.

Safety considerations for patient use of cannabis.

Medical marijuana administration considerations.

Ethical considerations related to the care of a patient using medical marijuana.

APRN role regarding certifying a qualifying condition.

The effectiveness of the educational video was evaluated by the nine-item postvideo survey which was identical to the pre-video survey (see Appendix A) with the addition of a question which asked students if they completed the online educational video. Participants rated their perceived current level of knowledge for each of the nine items using the same Likert scale as Ziemianski et al. (1: very poor; 2: somewhat poor; 3: undecided; 4: somewhat good; and 5: very good).

Additionally, both pre- and post-video surveys included a question which asked respondents to rate their perceived level of importance of integrating education on cannabis into the APRN curriculum. They rated their perceived level of importance using a 5-point-Likert scale (1: not at all important; 2: slightly important; 3: neutral; 4:

moderately important; 5: extremely important). The mean perceived level of importance 
was calculated for all pre-video survey responses, calculated for all post-video survey responses, and the difference between the post-video and pre-video means was calculated.

\section{Outcomes}

The short-term outcome of the educational video was to increase APRN student essential knowledge on medical cannabis and provide them with the NCSBN recommended essential knowledge elements for medical marijuana education in APRN nursing programs. Though beyond the scope of this project, the long-term goal is to incorporate the NCSBN recommended essential knowledge content into all accredited APRN education programs. Providing APRN students with principles to guide safe and knowledgeable practice will promote patient safety when caring for patients using cannabis.

\section{Data Analysis}

Descriptive statistics summarize respondents' knowledge ratings. Data were entered and analyzed using Microsoft Excel. Perceived current level of knowledge prevideo was calculated by computing the mean respondent score for each item. The mean perceived level of knowledge post-video score was also calculated for each of the nine items. The increase in perceived level of knowledge was calculated by finding the difference between the mean response score for each of the nine pre-video survey questions and the mean response score for all post-video survey questions. Change in perceived level of importance with regard to integrating education on cannabis into the APRN curriculum was calculated by computing the difference in between the mean score for this item on pre-video and post-video surveys. 
Data were analyzed for the survey question which asked respondents to rate their perceived level of importance of integrating education on cannabis into the APRN curriculum. Based on their perceived level of importance rating, the mean perceived level of importance was calculated for all pre-video survey responses, calculated for all postvideo survey responses, and the difference between the post-video and pre-video means was calculated.

Next, the results will be presented. 


\section{Results}

\section{Participants' Demographics}

Participants in this study included Rhode Island College graduate nursing students enrolled in Advanced Pharmacology, Nurs 505, in the Fall of 2019 or Spring of 2020, as well as those graduate students enrolled in Nurs 620 during Spring of 2020. A total of 24 students completed the pre-video survey and a total of 19 students completed the postvideo survey.

\section{Perceived Level of Knowledge Before Educational Video}

Table 3 illustrates the analysis of study participants' perceived level of knowledge on the nine knowledge area questions on the pre-video survey. The mean of all participant pre-video scores for all nine areas are presented.

\section{Table 3}

Analysis of Perceived Level of Knowledge Before Educational Module

\begin{tabular}{ll}
\hline Knowledge items & Mean knowledge score \\
(1-5) & 2.96 \\
\hline $\begin{array}{l}\text { - Current state of legalization of medical and } \\
\quad \text { recreational cannabis use. }\end{array}$ & 1.96 \\
2 - Principles of a Medical Marijuana Program (MMP). & 1.92 \\
3 - The endocannabinoid system, cannabinoid receptors, & \\
$\quad$ cannabinoids, and the interactions between them. & 2.04 \\
4 - Cannabis pharmacology and research associated with & \\
$\quad$ the medical use of cannabis. & 2.54 \\
5 - Signs and symptoms of cannabis use disorder and & \\
$\quad$ cannabis withdrawal syndromes. & 2.67 \\
6 - Safety considerations for patient use of cannabis. & 2.54 \\
7 - Medical marijuana administration considerations. & 2.67 \\
8 - Ethical considerations related to the care of a patient & \\
$\quad$ using medical marijuana. & 1.83 \\
9 - APRN role regarding certifying a qualifying condition. &
\end{tabular}


Mean knowledge scores ranged from $1.83 / 5.0$ to $2.96 / 5.0$. Prior to watching the educational video, respondents perceived that they were most knowledgeable about current state of legalization (2.96/5.0), safety considerations $(2.67 / 5.0)$, ethical considerations (2.67/5.0), signs and symptoms of cannabis use disorder and cannabis withdrawal (2.54/5.0), and administration considerations (2.54/5.0). In contrast, the lowest mean perceived level of knowledge was for the APRN role (1.83/5.0), the endocannabinoid system (1.92/5.0), principles of a Medical Marijuana Program (1.96/5.0), and cannabis pharmacology (2.04/5.0).

\section{Perceived Level of Knowledge Post Educational Video}

Table 4 illustrates the analysis of study participants' perceived level of knowledge on the nine knowledge area questions on the post-video survey. The mean of all participant post-video scores for all nine areas are presented on the next page. 


\section{Table 4}

Analysis of Perceived Level of Knowledge After Educational Module

\begin{tabular}{lc|}
\hline Knowledge items & Mean knowledge score (1-5) \\
\hline $\begin{array}{l}\text { - Current state of legalization of medical and } \\
\text { recreational cannabis use. }\end{array}$ & 4.63 \\
2 - Principles of a Medical Marijuana Program (MMP). & 4.53 \\
3 - The endocannabinoid system, cannabinoid receptors, & 4.58 \\
$\quad$ cannabinoids, and the interactions between them. & 4.42 \\
4 - Cannabis pharmacology and research associated with & \\
the medical use of cannabis. & 4.79 \\
5 - Signs and symptoms of cannabis use disorder and & 4.74 \\
$\quad$ cannabis withdrawal syndromes. & 4.74 \\
6 - Safety considerations for patient use of cannabis. & 4.63 \\
7 - Medical marijuana administration considerations. & \\
8 - Ethical considerations related to the care of a patient & 4.47 \\
$\quad$ using medical marijuana. & \\
9 - APRN role regarding certifying a qualifying condition. & \\
\end{tabular}

The mean score on all post-video survey knowledge items ranged from 4.42/5.0 to 4.79/5.0. Following the educational video, respondents perceived that they had a greater than "somewhat good" level of knowledge on all knowledge items. They had the highest perceived knowledge on signs and symptoms of cannabis use disorder and cannabis withdrawal syndromes (4.79/5.0), safety considerations for patient use of cannabis (4.79/5.0), and medical marijuana administration considerations (4.74/5.0). 
Table 5 illustrates the analysis of the increase in study participants' perceived level of knowledge following the educational video.

Table 5

Analysis of Difference in Perceived Level of Knowledge Pre-and Post-Educational Module

\begin{tabular}{lc}
\hline Knowledge items & $\begin{array}{c}\text { Change in knowledge } \\
\text { score (1-5) }\end{array}$ \\
\hline 1 - Current state of legalization of medical and & +1.67 \\
$\quad$ recreational cannabis use. & +2.57 \\
2 - Principles of a Medical Marijuana Program (MMP). & +2.66 \\
3 - The endocannabinoid system, cannabinoid receptors, & \\
$\quad$ cannabinoids, and the interactions between them. & +2.38 \\
4 - Cannabis pharmacology and research associated with & \\
$\quad$ the medical use of cannabis. & +2.25 \\
5 - Signs and symptoms of cannabis use disorder and & +2.07 \\
$\quad$ cannabis withdrawal syndromes. & +2.20 \\
6 - Safety considerations for patient use of cannabis. & +1.96 \\
7 - Medical marijuana administration considerations. & \\
8 - Ethical considerations related to the care of a patient & +2.64 \\
$\quad$ using medical marijuana. & \\
9 - APRN role regarding certifying a qualifying condition. & \\
\hline
\end{tabular}

The survey knowledge items with the greatest increase in perceived level of knowledge (i.e., perceived level of knowledge post-video - perceived level of knowledge pre-video) following the educational video were as follows: the endocannabinoid system; cannabinoid receptors; cannabinoids; and the interactions between them, the APRN role regarding certifying a qualifying condition; and principles of a Medical Marijuana Program. While the mean perceived level of knowledge on pre-video knowledge items ranged from 1.83-2.96/5.0, the mean on all post-video knowledge items ranged from $4.44-4.79 / 5.0$. 


\section{Importance of Cannabis Education}

Table 6 illustrates the analysis of study participants' perceived level of importance with regard to integrating education on cannabis into the APRN curriculum.

Table 6

Analysis of Difference in Perceived Level of Importance of Education on Cannabis in APRN Curriculum

\begin{tabular}{|lc|}
\hline & Mean score (1-5) \\
\hline Pre-Video Survey & 4.45 \\
Post-Video Survey & 4.76 \\
\hline
\end{tabular}

The mean score for the perceived importance of integrating cannabis education into the APRN curriculum increased from 4.45/5.0 on pre-video surveys to $4.77 / 5.0$ on post-video surveys.

Next, the summary and conclusions will be presented. 


\section{Summary and Conclusions}

As interest in medical cannabis continues to grow in the United States, healthcare providers, including APRNs, will be faced with increasing requests for information and guidance from patients regarding the use of medical cannabis for health-related issues. With federal regulations allowing APRNs to certify a qualifying condition, APRNs may also become a major source of education, decision support, and access for patients. Literature has examined the knowledge and practice gaps related to medical cannabis in a national sample of Canadian physicians and nurse practitioners and the findings have demonstrated a strong need for education on all aspects of cannabis (Balneaves et al., 2018; Ziemianski et al., 2015).

The NCSBN study (2018) results informed specific guidelines: nursing care of the patient using medical marijuana; medical marijuana education in pre-licensure nursing programs; medical marijuana education in APRN nursing programs; and APRNs certifying a medical marijuana qualifying condition. The Logic Model (2004) was used as a framework to effectively plan the and incorporate the NCSBN guidelines into an effective educational module, implement the intervention, and evaluate the outcome of the project.

The purpose of the project focused on evaluating the impact of the educational module designed to provide the NCSBN essential knowledge elements of medical cannabis to the APRN student. The educational module was a 30-minute narrated PowerPoint presentation which students viewed at home as part of their course curriculum. A pre-video survey was used to determine perceived current level of knowledge of medical cannabis among APRN student participants prior to watching the 
educational video and a post-video survey was administered after student completion of the video to measure improved knowledge.

Descriptive statistics summarized respondents' knowledge ratings on both preand post-video surveys. The change in perceived level of knowledge following the educational video was calculated by finding the difference between the mean response score for each of the nine pre-video survey questions and the mean response score for all post-video survey questions. An additional survey question asked respondents to rate their perceived level of importance with regard to integrating education on cannabis into the APRN curriculum. The change in response following the educational module for this question was also calculated by computing the difference in the mean score for this item on pre-video and post-video surveys.

When using the NCSBN guidelines for medical marijuana education in APRN nursing programs, and the nine essential knowledge recommendations, this project demonstrated that, at baseline APRN students' perceived level of knowledge for all knowledge items was between very poor and neutral. If the knowledge items represent essential knowledge necessary to provide safe patient care to patients using medical or recreational cannabis, this low level of perceived knowledge is concerning. This low level of perceived knowledge also supports the integration of these essential knowledge recommendations into APRN curriculum in order to best care for the increasing number of patients using cannabis.

The largest knowledge gaps identified were related to background knowledge of cannabis, the endocannabinoid system, cannabis pharmacology, and the APRN role in certifying a qualifying condition. This knowledge could easily be integrated into the 
theory component of upper level course curriculum. Advanced practice registered nurse students perceived their knowledge of the more clinical elements better but still somewhat poor. These knowledge elements, such as signs and symptoms of cannabis use disorder and cannabis withdrawal syndrome, safety considerations, administration considerations, and ethical considerations could most likely be incorporated into the clinical competency portion of the curriculum. Students could be encouraged to address these elements with at least one patient over the course of their 600-direct-patient-carehour requirement.

Another option for increasing APRN students' perceived level of knowledge related to cannabis would be the integration of an educational video module similar to the one developed for this study. The video module provided the APRN student with pertinent information related to each of the nine essential knowledge elements outlined by the NCSBN study. Following the video, APRN students perceived knowledge was at least "somewhat good", if not "very good" on all nine items. Furthermore, prior to the educational video, students rated their perceived level of knowledge as "somewhat good" or "very good" only $22 \%$ of the time compared to $99 \%$ of the time after watching the video. If "somewhat good" or "very good" perceived level of knowledge is identified as the goal which curriculum should meet, the educational video intervention met the goal of increasing student perceived level of knowledge to an adequate level. Students perceived that their level of knowledge increased the most in the knowledge items related to principles of a Medical Marijuana Program, the endocannabinoid system, and the APRN role regarding certifying a qualifying condition. 
The APRN student respondents perceived the importance of integrating education on cannabis into the APRN curriculum as moderately and extremely important both before and after watching the educational video. This perceived level of importance suggests that students believe that knowledge related to cannabis is, and/or will be, essential to their role as an APRN. Students expect that curriculum is preparing them with the knowledge necessary to fulfill the APRN role and provide appropriate and safe patient care. Thus, APRN student perception that integration of cannabis education into the APRN curriculum is moderately to extremely important may support funding for a gap analysis and proposed areas of integration into current course curriculum.

Limitations to these findings must be noted such as the small sample size, which represented only a small percentage of APRN students. As a convenience sample, APRN students who participated in the study may have held a unique perspective or interest in medical cannabis not representative of the larger APRN student or APRN community. Also, due to the fact that watching the educational video was an ungraded course assignment, there was no way to confirm whether all participants completing post-video surveys had completed the educational module.

In summary, given the limited amount of knowledge related to medical cannabis in the current APRN curriculum together with the increasing prevalence of its use, the findings remain relevant and will inform future education programming.

Next, recommendations and implications for APRN education and practice. 


\section{Recommendations and Implications for Advanced Nursing Practice}

As the demand for medical cannabis increases and the prevalence of patients using cannabis for medical purposes continues to rise, education within APRN programs, as well as continuing education for those in practice, is urgently needed to ensure safe patient care. The NCSBN National Nursing Guidelines for Medical Marijuana Education in APRN Nursing Programs, which outlines nine essential knowledge principles necessary for APRN students, should be reviewed and incorporated into accredited APRN course curriculum. Accredited programs should perform a gap analysis in order to identify existing content and course objectives, as well as to identify the most appropriate content areas to integrate the recommended knowledge principles.

Advanced practice registered nursing education should include essential knowledge such as: the current state of legalization of medical and recreational cannabis use; principles of an MMP; the endocannabinoid system, cannabinoid receptors, cannabinoids, and the interactions between them; cannabis pharmacology and the research associated with medical use of cannabis; signs and symptoms of cannabis use disorder and cannabis withdrawal syndrome; safety considerations for patient use of cannabis, medical marijuana administration considerations; ethical considerations related to the care of a patient using medical marijuana; and the need to follow specific employer policies and procedures, standard of care arrangements, and facility policy and procedures regarding certifying a qualifying condition.

Integration of essential medical cannabis knowledge into APRN education can be accomplished by following the NCSBN National Nursing Guidelines for Medical Marijuana Education in APRN Nursing Programs and expanding various areas of 
program curriculum. For example, essential cannabis knowledge could be integrated into advanced pharmacology course content through the development of a tailored online education program or educational video inclusive of all knowledge elements such as the video used in this project. Essential knowledge could be added to lecture material or assigned as additional course required material or reading. Online continuing professional development and in-person seminars, fulfilling student conference hour requirements, is another educational strategy option.

Additionally, there is an ongoing need for clinical evidence-based research on the use of cannabis for medical purposes. A more robust body of literature will best inform clinical practice guidelines and support all healthcare practitioners in providing effective and safe patient care. More information regarding student APRN and licensed APRN knowledge, attitudes, and beliefs surrounding medical cannabis is necessary to inform the most effective educational strategies for integrating knowledge into curriculum and continuing education.

As the APRN scope of practice authorizes certification of a qualifying condition, APRNs need to be supported and provided education appropriate to fulfill this role and provide safe patient care. As state legislative bodies create MMP requirements, policy should ensure a minimum educational requirement for medical cannabis be met by certifying practitioners. Similar to the mandatory opioid/pain management CEUs many states have adopted, states with MMPs should mandate medical cannabis CEUs to ensure providers have a basic knowledge necessary to appropriately care for this expanding patient population. In the meantime, nursing regulatory organizations, government agencies, and academic institutions must work collaboratively to identify knowledge 
gaps, tailor educational programs, and outline clinical competencies specific to medical cannabis knowledge clinicians will use in practice.

In summary, recommending medical cannabis and certifying a medical marijuana qualifying condition is within the APRN scope of practice within US jurisdictions which have legalized cannabis for medical use. As licensed healthcare providers, APRNs are responsible for maintaining or seeking knowledge and clinical competency related to patient-care needs and clinical practice. In order to ensure safe and appropriate patient care, APRN programs must stay up-to-date on matters of common interest and concern affecting the public health, safety, and welfare. Educational programs must also ensure curriculum supports the development of knowledge applicable to licensing examinations which organization such as the NCSBN aid in developing. 


\section{References}

American Nurses Association (ANA). (2018). Advanced Practice Registered Nurse $(A P R N)$. Retrieved from https://www.nursingworld.org/practicepolicy/workforce/what-is-nursing/aprn/

American Psychiatric Association (APA). (2013). Diagnostic and statistical manual of mental disorders (5th ed.). Arlington, VA: American Psychiatric Publishing.

Balneaves, L.G., Alraja, A., Ziemianski, D., McCuaig, F., and Ware, M. (2015). A national needs assessment of Canadian nurse practitioners regarding cannabis for therapeutic purposes. Cannabis and Cannabinoid Research, 3(1), 66-73. Doi: 10.1089/can.2018.0002.

Batalla, A., Bhattacharyya, S., Yucel, M., Fusar-Poli, P., Crippa, J.A., Nogue, S., Torrens, M., Pujol, J., Farre, M., and Martin-Santos, R. (2013). Structural and functional imaging studies in chronic cannabis users: a systematic review of adolescent and adult findings. PLoS One, 8(2), e55821. Doi: 10.1371/journal.pone.0055821.

Bridgeman, M.B. and Abazia, D.T. (2017). Medical cannabis: History, pharmacology, and implications for the acute care setting. $P \& T, 42(3), 180-188$.

Crean, R.D., Crane, N.A., and Mason, B.J. (2011). An evidence based review of acute and long-term effects of cannabis use on executive cognitive functions. J Addict Med, 5(1), 1-8. Doi: 10.1097/ADM.0b013e31820c23fa.

Devinsky, O., Cilio, M.R., Cross, H., Fernandez-Ruiz, J., French, J., Hill, C., Katz, R., Di Marzo, V., Jutras-Aswad, D., Notcutt, W.G., Martinez-Orgado, J., Robson, P.J., Rohrback, B.G., Thiele, E., Whalley, B., and Friedman, D. (2014).

Cannabidiol: pharmacology and potential therapeutic role in epilepsy and other neuropsychiatric disorders. Epilepsia, 55(6), 791-802. Doi: 10.1111/epi.12631.

Drug Enforcement Administration (DEA). (2016). Denial of Petition to Initiate Proceedings to Reschedule Marijuana. Retrieved from www.gpo.gov/fdsys/granule/FR-2016- 08-12/2016-17954.

Frost, L., Mostofsky, E., Rosenbloom, J.I., Mukamal, K.J., and Mittleman, M.A. (2013). Marijuana use and long-term mortality among survivors of acute myocardial infarction. Am Heart J, 165, 170-175.

Grotenhermen, F. (2004). Pharmacology of cannabinoids. Neuroendocrinology Letters, 25(1/2), 14-23.

Harris, A.D., McGregor, J.C., Perencevich, E.N., Furuno, J.P., Zhu, J., Peterson, D.E., and Finkelstein, J. (2006). The use and interpretation of quasi-experimental studies in medical informatics. Journal of American Medical Informatics Association, 13(1), 16-23. Doi: 10.1197/jamia.M1749. 
Hazekamp, A., Ware, M.A., Muller-Vahl, K.R., Abrams, D. and Grotenhermen, F. (2013). The medicinal use of cannabis and cannabinoids - an international crosssectional survey on administration forms. Journal of Psychoactive Drugs, 45, 199-210.

Huang, Y.H., Zhang, Z.F., Tashkin, D.P., Feng, B., Straif, K., and Hashibe, M. (2015). An epidemiologic review of marijuana and cancer: an update. Cancer Epidemiology and Biomarkers Prev, 24(1), 15-31. Doi: 10.1158/1055-9965.

Kattoor, M.D. and Mehta, J.L. (2016). Marijuana and coronary heart disease. American College of Cardiology Online. Retrieved from https://www.acc.org/latest-incardiology/articles/2016/09/22/08/58/marijuana-and-coronary-heart-disease.

Kumar, R.N., Chambers, W.A., and Pertwee, R.G. (2001). Pharmacological actions and therapeutic uses of cannabis and cannabinoids. Anaesthesia, 56, 1059-1068.

Logic Model. Encyclopedia of Evaluation. Sage Publications, Inc. doi:10.4135/9781412950558.n321.

Lu, H.C. and Mackie, K. (2016). An introduction to the endogenous cannabinoid system. Biological Psychiatry, 79(7), 516-525. Doi: 10.1016/j.biopsych.2015.07.028.

Renger, R. (2002). A three-step approach to teaching logic models. The American Journal of Evaluation, 23(4), 493-503. doi:10.1016/s1098-2140(02)00230-8.

Rosenberg, C. (2016). Applications to become registered under the controlled substances act to manufacture marijuana to supply researchers in the United States. Retrieved from https://www.federalregister.gov/ documents/2016/08/12/2016-17955/applications-to-become-registered-under-thecontrolled-substances-act-to-manufacture-marijuana-to.

Rosenberg, C. (2016). Denial of petition to initiate proceedings to reschedule marijuana. Retrieved from https://www.federalregister.gov/ documents/2016/08/12/2016-17960/denial-of-petition-to-initiate-proceedings-toreschedule-marijuana.

Mackie, K. (2008). Cannabinoid receptors: where they are and what they do. Journal of Neuroendocrinology, 20(Suppl 1), 10-41. Retrieved from http://onlinelibrary.wiley.com/ doi/10.1111/j.1365-2826.2008.01671.x/full

Madras, B. (2015). Update of cannabis and its medical use. Retrieved from http://www.who.int/medicines/access/controlled-substances/6_2_ cannabis_update.pdf.

Mandelbaum, D.E. and de la Monte, S.M. (2017). Adverse structural and functional 
effects of marijuana on the brain: evidence reviewed. Pediatric Neurology, 66, $12-$ 20. Doi: 10.1016/j.pediatrneurol.2016.09.004.

Medscape. (2006). FDA Approvals: Lumigan, Cesamet, Omnitrope. Retrieved from https://www.medscape.com/viewarticle/540937.

Meier, M.H., Caspi, A., Ambler, A., Harrington, H.L., Houts, R., Keefe, R., McDonald, K., Ward, A., Poulton, R., and Moffitt, T.E. (2012). Persistent cannabis users show neuropsychological decline from childhood to midlife. PNAS, 109(40), E2657-E2664.

Moore, M. (2018). How the endocannabinoid system was discovered. Retrieved from https://www.labroots.com/trending/cannabis-sciences/8456/endocannabinoidsystem-discovered

Mukamal, K.J., Maclure, M., Muller, J.E., and Mittleman, M.A. (2008). An exploratory prospective study of marijuana use and mortality following acute myocardial infarction. Am Heart J, 155, 465-470.

Nader, D.A. and Sanchez, Z.M. (2018). Effects of regular cannabis use on neurocognition, brain structure, and function: a systematic review of findings in adults. American Journal of Drug and Alcohol Abuse, 44(1), 4-18. Doi: 10.1080/00952990.2017.1306746.

National Academies of Sciences, Engineering, and Medicine. (2017). The health effects of cannabis and cannabinoids: The current state of evidence and recommendations for research. Washington, DC: National Academies Press.

National Conference of State Legislatures (NCSL). (2020). State medical marijuana laws. Retrieved from http://www.ncsl.org/research/health/state-medicalmarijuana-laws.aspx.

National Council of State Boards of Nursing (NCSBN) APRN Advisory Committee. (2008). Consensus model for APRN regulation: licensure, accreditation, certification, and education. Retrieved from https://ncsbn.org/Consensus_Model_for_APRN_Regulation_July_2008.pdf

Osuch, E.A., Manning, K., Hegele, R.A., Theberge, J., Neufeld, R., Mitchell, D., Williamson, P., and Gardner, R.C. (2016). Depression, marijuana use and earlyonset marijuana use conferred unique effects on neural connectivity and cognition. Acta Psychiatrica Scandinavica, 134(5), 399-409.

Park, S. and Myung, S.K. (2018). Cannabis smoking and risk of cancer: A meta-analysis of observational studies. Journal of Global Oncology, 4(Supplement 2), 196s196s. 
Schmitz, C.C., and Parsons, B.A. (1999). Everything you wanted to know about logic models but were afraid to ask. Battle Creek, MI: W.K. Kellogg Foundation.

Schwertz, D.W., Piano, M.R., Kleinpell, R., and Johnson, J. (1997). Teaching pharmacology to advanced practice nursing students: issues and strategies. $A A C N$ Clinical Issues, 8(1), 132-146.

Shakman, K. and Rodriguez, S.M. (2015). Logic models for program design, implementation, and evaluation: workshop toolkit. U.S. Department of Education, Institute of Educational Sciences (IES) Report. Retrieved from https:/files.eric.ed.gov/fulltext/ED556231.pdf

Sidney, S., Beck, J.E., Tekawa, I.S., Quesenberry, C.P., and Friedman, G.D. (1997). Marijuana use and mortality. Am J Public Health, 87, 585-590.

Sonon, K.E., Richardson, G.A., Cornelius, J.R., Kim, K.H., and Day, N.L. (2015). Prenatal marijuana exposure predicts marijuana use in young adulthood. Neurotoxicol Teratol. 47, 10-15. Doi: 10.1016/j.ntt.2014.11.003.

Stinson, F.S., Ruan, W.J., Pickering, R., and Grant, B.F. (2006). Cannabis use disorders in the USA: prevalence, correlates and co-morbidity. Psychol Med. 36(10),14471460 .

Stout, S. M., \& Cimino, N. M. (2014). Exogenous cannabinoids as substrates, inhibitors, and inducers of human drug metabolizing enzymes: a systematic review. Drug Metabolism Reviews, 46(1), 86-95.

Substance Abuse and Mental Health Services Administration. (2017). Key substance use and mental health indicators in the United States: Results from the 2016 National Survey on Drug Use and Health. Rockville, MD: Center for Behavioral Health Statistics and Quality, Substance Abuse and Mental Health Services Administration. Retrieved from https://www. samhsa.gov/data/

The National Academies of Sciences, Engineering, and Medicine. (2017). The health effects of cannabis and cannabinoids: the current state of evidence and recommendations for research. Retrieved from nationalacademies.org/CannabisHealthEffects.

The National Council of State Boards of Nursing. National Nursing Guidelines for Medical Marijuana. Journal of Nursing Regulations, 9 (2), S1-S60. Retrieved from https://www.ncsbn.org/The_NCSBN_National_Nursing_Guidelines_ for_Medical_Marijuana_JNR_July_2018.pdf. 
United Nations. (1961). Single convention on narcotic drugs: as amended by the 1972 protocol amending the single convention on narcotic drugs, 1961. United Nations, Treaty Series, 1019(1). Retrieved from https://www.unodc.org/pdf/convention 1961_en.pdf.

United Nations Office on Drugs and Crime (UNODC). (2019). World Drug Report. Retrieved from: https://wdr.unodc.org/wdr2019/

U.S. Food and Drug Administration (FDA). (2019). FDA regulation of cannabis and cannabis-derived products: questions and answers. Retrieved from https://www.fda.gov/news-events/public-health-focus/fda-regulation-cannabisand-cannabis-derived-products-questions-and-answers\#approved

U.S. Food and Drug Administration (FDA). (2004). Marinol (dronabinol) capsules. Retrieved from https://www.fda.gov/ohrms/dockets/dockets/05n0479/05N-0479emc0004-04.pdf.

W.K. Kellogg Foundation. (2004). Using Logic Models to bring together planning, evaluation, and action: Logic Model development guide. Retrieved from https://www.bttop.org/sites/default/files/public/W.K.\%20Kellogg\%20LogicModel .pdf

Wadsworth, E.J., Moss, S.C., Simpson, S.A., and Smith, A.P. (2006). Cannabis use, cognitive performance and mood in a sample of workers. J Psychopharmacol, 20(1), 14-23.

Wang, T., Collet, J.P., Shapiro, S., and Ware, M.A. (2008). Adverse effects of medical cannabinoids: a systematic review. CMAJ, 178(13), 1669-1678. Doi: 10.1503/cmaj.071178.

Whalen, K. (2019). Pharmacology, $7^{\text {th }}$ edition. Lippincott Illustrated Reviews Series: Wolters Klower.

Whiting, P. F., Wolff, R. F., Deshpande, S., Di Nisio, M., Duffy, S., Hernandez, A., Keurentjes, C., Lang, S., Misso, K., Ryder, S., Schmidlkofer, S., Westwood, M., and Kleijnen, J., (2015). Cannabinoids for medical use: a systematic review and meta-analysis. JAMA, 313(24), 2456-2473. Doi: 10.1001/jama.2015.6358.

World Health Organization. (2019). International Statistical Classification of Diseases and Related Health Problems (11th ed.; ICD-11).

Ziemianski, D., Capler, R., Tekanoff, R., Lacasse, A., Luconi, F., and Ware, M., (2015). Cannabis in medicine: a national educational needs assessment among Canadian physicians. BMC Medical Education. https://doi.org/10.1186/s12909-015-0335-0 
Zhu, H. and Wu, L.T. (2016). Trends and correlates of cannabis-involved emergency department visits: 2004 to 2011. J Addict Med. 10(6), 429-436. Doi: 10.1097/ADM.00000000000256.

Zou, S. and Kumar, U. (2018). Cannabinoid receptors and the endocannabinoid system: signaling and function in the central nervous system. Int J Mol Sci, 19(3), 833. Doi: 10.3390/ijms19030833. 


\section{Appendix A}

\section{PRE-ASSIGNMENT SURVEY}

1) Please rank your perceived current level of knowledge on the nine (9) cannabis-related topics below.

$5=$ very good $\quad 4=$ somewhat good $\quad 3=$ undecided $\quad 2=$ somewhat poor $\quad 1=$ very poor

\begin{tabular}{|c|c|c|c|c|c|}
\hline Knowledge area & & & & & \\
\hline $\begin{array}{l}1 \text { - Current state of legalization of medical and recreational } \\
\text { cannabis use. }\end{array}$ & 5 & 4 & 3 & 2 & 1 \\
\hline 2 - Principles of a Medical Marijuana Program (MMP) & 5 & 4 & 3 & 2 & 1 \\
\hline $\begin{array}{l}3 \text { - The endocannabinoid system, cannabinoid receptors, } \\
\text { cannabinoids, and the interactions between them. }\end{array}$ & 5 & 4 & 3 & 2 & 1 \\
\hline $\begin{array}{l}4 \text { - Cannabis pharmacology and research associated with the } \\
\text { medical use of cannabis. }\end{array}$ & 5 & 4 & 3 & 2 & 1 \\
\hline $\begin{array}{l}5 \text { - Signs and symptoms of cannabis use disorder and cannabis } \\
\text { withdrawal syndrome. }\end{array}$ & 5 & 4 & 3 & 2 & 1 \\
\hline 6 - Safety considerations for patient use of cannabis. & 5 & 4 & 3 & 2 & 1 \\
\hline 7 - Medical marijuana administration considerations. & 5 & 4 & 3 & 2 & 1 \\
\hline $\begin{array}{l}8 \text { - Ethical considerations related to the care of a patient using } \\
\text { medical marijuana. }\end{array}$ & 5 & 4 & 3 & 2 & 1 \\
\hline 9 - APRN role regarding certifying a qualifying condition. & 5 & 4 & 3 & 2 & 1 \\
\hline
\end{tabular}

2) In terms of integrating education on cannabis into the APRN curriculum, please circle your perceived level of importance.

5 = Extremely important

4 = Moderately important

$3=$ Neutral

$2=$ Slightly important

$1=$ Not at all important 